Working Paper 2010:21

Department of Economics

\title{
Does the Labor-Income Process Contain a Unit Root? Evidence from Individual- Specific Time Series
}

Magnus Gustavsson and Pär Österholm 
Department of Economics

Working paper 2010:21

Uppsala University

December 2010

P.O. Box 513

ISSN 1653-6975

SE-751 20 Uppsala

Sweden

Fax: +46184711478

Does the Labor-Income Process Contain a Unit Root?

EVIDENCE FROM INDIVIDUAL-SPECIFIC TIME SERIES

Magnus Gustavsson and Pär Österholm

Papers in the Working Paper Series are published on internet in PDF formats.

Download from http://www.nek.uu.se or from S-WoPEC http://swopec.hhs.se/uunewp/ 


\title{
Does the Labor-Income Process Contain a Unit Root? Evidence from Individual-Specific Time Series*
}

\author{
Magnus Gustavsson* \\ Department of Economics, Uppsala University \\ Uppsala Center for Labor Studies \\ and \\ Pär Österholm ${ }^{\#}$ \\ National Institute of Economic Research
}

9th of December, 2010

\begin{abstract}
Employing econometric methods for univariate time series, this paper investigates the empirical validity of assuming a unit root in individuals' labor-income processes. Using a Swedish register-based longitudinal dataset which allows us to follow a cohort of workers from 1968 to 2005, we are able to obtain distributions of median unbiased estimates of localto-unity parameters. The results indicate that earnings for the representative worker are governed by a process where shocks to earnings have fairly high persistence but are both economically and statistically significantly different from having permanent effects; that is, the largest autoregressive root is less than unity. These results add to the studies that question the heavy use of unit-root processes for earnings in calibrations of life-cycle models.
\end{abstract}

JEL Classification: C22; C23; J31

Keywords: Idiosyncratic income risk; Unit-root model; Earnings dynamics; Local-to-unity parameter

\footnotetext{
* We are grateful to Per-Anders Edin, Nils Gottfries and seminar participants at Uppsala University for valuable comments.

* Department of Economics, Uppsala University, Box 513, 75120 Uppsala, Sweden.

Telephone: +46 18471 1103. Email: magnus.gustavsson@ nek.uu.se

\# National Institute of Economic Research, Box 3116, 10362 Stockholm, Sweden.

Telephone: +46 84535972 Email: par.osterholm@konj.se
} 


\section{Introduction}

How to best model individuals' earnings and wage dynamics has important implications for several fields in economics. In particular, it plays a key role in our understanding of idiosyncratic labor-income risk and thereby for many of individuals' life-cycle decisions related to consumption and saving (for an overview, see Meghir and Pistaferri, 2010). Other important fields include the relevance of models that aim to explain individual's earnings trajectories (Baker, 1997; Neal and Rosen, 2000), questions related to the incidence and persistence of low income spells (Atkinson et al., 1992) and how to best model the time-series variation in earnings distributions (Moffitt and Gottschalk, 2002; Baker and Solon, 2003).

The currently most applied model of individuals' earnings dynamics is a labor-income process where earnings are subject to idiosyncratic shocks with permanent effects. In particular, contemporary research based on calibrations of life-cycle and overlapping generations models rely heavily on this framework (cf. Guvenen, 2007, 2009). Since such a process, which we henceforth refer to as the unit-root (UR) model, is nonstationary, it exhibits distinct features that set it apart from other reasonable representations of individual earnings. Obviously, it induces maximum persistence in shocks to income. It also means that the variance of the forecast error of earnings does not converge to a constant value - as it does for a (trend-) stationary process - but grows linearly with the forecast horizon; all else equal, this induces more income risk on the individual. These properties have been shown to matter for conclusions in a wide array of topics related to life-cycle consumption, precautionary saving, portfolio behavior, and labor supply; see, for example, Kimball (1990), Carroll and Samwick (1998), Davis and Willen (2000), Low (2005), and Meghir and Pistaferri (2010).

Given the important implications of the UR model, it is not surprising that a substantial literature has tried to test its empirical validity. These studies can be divided into two strands. The first recognizes that the UR process implies testable implications for the lag structure of the autocovariance matrix of earnings. Conclusions from this part of the literature are dispersed though. ${ }^{1}$ Researchers have also raised serious doubt about the validity of this approach since $i$ ) the statistical tests are associated with poor power (Baker, 1997; Guvenen, 2009), and ii) parametric models fitted to the autocovariance structure are sensitive to the

\footnotetext{
${ }^{1}$ Studies that report evidence in favor of the UR model include MaCurdy (1982), Abowd and Card (1989), and Meghir and Pistaferri (2004). Studies that find evidence against the UR model include Palme (1995), Baker (1997), and Guvenen (2009).
} 
exact choice of functional form (Baker and Solon, 2003). The second strand has deduced information about labor income processes by comparing theoretical predictions of individuals' life-cycle consumption behavior to that of actual data. Up until quite recently, this part of the literature was nearly undivided in favor of the UR model, which - together with the mixed results from labor-income data - probably explains the heavy use of the UR model in calibrations. ${ }^{2}$ However, the more recent work of Guvenen (2007) shows that a trendstationary process along the lines of Mincer's (1974) human capital model also can match the patterns in consumption if individuals' gradually learn about their earnings trajectories in a Bayesian fashion. Succeeding research by Guvenen and Smith (2010) further shows that the trend-stationary model of Guvenen (2007) induces significantly smaller lifetime income risk than what is typically assumed in most calibrated models.

In this paper, we address the question of the UR model's validity in a new way. Our study belongs to the field that use earnings rather than consumption data, but instead of focusing on indirect implications for the autocovariance structure, as has been commonly done in the literature, we employ direct methods with their origins in univariate time-series econometrics. Applying these methods to the individual-specific time series of earnings, we obtain distributions of the median unbiased estimate of the local-to-unity parameter which can be used to assess the relevance of the UR model for the representative worker.

Concretely, we have access to longitudinal register data of high quality without survey attrition which allows us to use time-series data for a birth cohort of Swedish men over the period 1968 and 2005, resulting in 38 years of consecutive labor-income data for over 2,400 individuals. With these data, we estimate individual-specific local-to-unity parameters for an autoregressive process governing the dynamics of each individual's relative earnings. When this parameter is equal to zero, individual earnings have a unit root; when it is less than zero, individual earnings are (trend-) stationary. Following Stock (1991) and Campbell and Yogo (2006), we invert a unit-root test statistic in order to get a median unbiased estimate of the local-to-unity parameter. This estimate has the appealing property that the probability of overestimation is equal to the probability over underestimation. Hence, estimating local-to-

\footnotetext{
${ }^{2}$ The significant rise in within-cohort consumption inequality observed over the life cycle has been hard to reconcile with an earnings process where individuals are able to predict future earnings but is consistent with the UR model; see, for instance, Deaton and Paxson (1994), Lucas (2003), and Storesletten et al. (2004). The observation that consumption growth parallels income growth over the life-cycle has also been interpreted as evidence in favor of the UR model; see, for instance, Carroll (1992) and Gourinchas and Parker (2002).
} 
unity parameters for each individual, we obtain empirical distributions of the local-to-unity parameter which allows us to draw inference about the likelihood of a unit root in individuals' earnings. In particular, the median of the distribution of the estimated local-to-unity parameters should be located at or close to zero if workers' data generating process for earnings contains a unit root. As it turns out, our empirical distributions have most of the mass located well below zero, suggesting that temporary rather than permanent effects of shocks to earnings are a better representation for the typical worker. This conclusion is in accord with contributions such as Baker (1997), Guvenen (2007, 2009), Browning et al. (2010), and Guvenen and Smith (2010).

The rest of the paper proceeds as follows. In Section 2, we present our data and the sample construction. In Section 3 we present our empirical framework and relate it to the previous literature. Section 4 contains a short discussion of the obtained results from applying statistical tests to the autocovariance structure of our earnings data. Section 5 presents and discusses the results for the UR model based on the local-to-unity framework. Finally, Section 6 concludes.

\section{Data}

The data used come from the Swedish longitudinal database LINDA, constructed to be crosssectionally representative of the Swedish population each year from 1968 onwards (Edin and Fredriksson, 2000). The database contains 3.35 percent of the Swedish population. All information is based on administrative registers which confers several advantages compared to an analysis based on survey data. First, there is no outflow apart from death or migration, so the data are free of the kind of sample attrition common in surveys such as PSID (see Fitzgerald et al., 1998). Second, the data are highly reliable; information from administrative registers is likely to be better than the recollection of individuals.

The analysis is based on annual labor earnings. ${ }^{3}$ Information on individuals' earnings comes from Statistics Sweden's Income Register. Up until 1981, this register is based on employees' tax reports under the provisions of the income tax laws. From 1982 onwards, it is based on employers' reports, also under the provisions of the income tax laws.

\footnotetext{
${ }^{3}$ The earnings variable is constructed following the recommendations in the LINDA documentation by Edin and Fredriksson (2000), and the reader is referred to this study for details.
} 
Our sample consists of Swedish men born in the years 1947 and 1948, which in turn is divided into three sub-samples corresponding to individuals with a primary education, highschool education, and college education, respectively. ${ }^{4}$ We use this particular two-year birth cohort since, between 1968 and 2005, its individuals are old enough to have completed their education and performed the mandatory year of Swedish military service but young enough not to be seriously affected by early retirement, while at the same time giving us the necessary number of time-series observations for each individual. Individuals with less than a college education are followed over the 38 years 1968-2005, corresponding to the ages 21/22-58/59, and individuals with a college education are followed over the period 1973-2005, corresponding to the age interval 26/27-58/59.

Following the standard in the literature (see Meghir and Pistaferri, 2010), we focus on individuals with positive annual earnings. To maximize the number of included individuals under the restriction of long enough and consistent time series, men with less than a college education are kept in the sample if they have positive earnings (above zero) in each year that follows after their first year of positive earnings, provided that this first year occurs prior to 1973. The corresponding individuals with a college education, which we start to study in 1973, need to have positive earnings in all their sample years. ${ }^{5}$ To ensure that each individual's time series is not made noisy by labor-market entry, we next discard the first year of earnings for each individual; that is, we only include consecutive years of positive earnings that have a preceding year of positive earnings. ${ }^{6}$ In the end, we have a working sample of 2,486 men, of which 741 have a primary-school education, 1,078 a high-school education, and 667 a college education.

\footnotetext{
${ }^{4}$ Individuals are assigned to an educational attainment level based on the information in LINDA in 2005.

${ }^{5}$ As a sensitivity analysis, we have also used a sample where individuals can be believed to have a stronger attachment to the labor market in each year. In this sample, we required consecutive years of earnings above the 'basic amount'. The basic amount is annually corrected for inflation and corresponds to 39,400 SEK in 2005, which translates to around 5,000 USD or 4,000 euro. An analysis based on this sample did not alter any conclusions; results are available on request.

${ }^{6}$ For example, the actual time-series used in the analysis for an individual with a high school education and zero earnings in 1968 but with consecutive years of positive earnings in the period 1969-2005 will cover the years 1970-2005.
} 


\section{The labor-income process and the empirical framework}

\subsection{The unit-root model}

Consider the following model for the logarithm of labor earnings in year $t$ for individual $i$ with educational attainment $s$ who belongs to birth cohort $b$ (in our case individuals born in 1947/48):

$y_{t}^{i, s, b}=d_{t}^{s, b}+r_{t}^{i}$

In equation (1), $d_{t}^{s, b}$ is a year-specific dummy variable for individuals belonging to the same birth cohort and with the same educational attainment level. This dummy variable will capture both the common life-cycle variation in earnings for this group as well as common aggregate shocks and/or time trends. The variable $r_{t}^{i}$ captures the individual-specific component of earnings, and hence also individual-specific changes in earnings. Since the focus in the literature and in this paper is on individual-specific earnings dynamics, the rest of the paper will focus on the time-series properties of $r_{t}^{i}$. In Appendix A, we depict some of the individual-specific time series of $r_{t}^{i}$ that results from using equation (1).

To place our analysis in context, consider next the following stylized decomposition of the process for $r_{t}^{i}$ which nests the most common specifications in the literature:

$r_{t}^{i}=\underbrace{\delta^{i}+\psi^{i} t}_{A}+\underbrace{\mu_{t}^{i}}_{B}$,

where

$\mu_{t}^{i}=\rho \mu_{t-1}^{i}+\varepsilon_{t}^{i}$

and $\varepsilon_{t}^{i}$ is white noise. In equation (2), $A$ describes a deterministic and $B$ a stochastic component, with individual earnings being governed by an individual-specific intercept and trend plus a stochastic autoregressive process of order one, $\operatorname{AR}(1)$. If $\rho$ in equation (3) is smaller than unity (in absolute value), earnings are trend stationary. If $\rho$ is equal to unity, 
earnings are non-stationary, with or without a drift depending on whether $\psi^{i} \neq 0$ or not (see, for example, Maddala and Kim, 1998).

Before proceeding, it is here important to recognize that the model in (2) could be extended to include additional and independent processes along the lines of that in expression (3), in order to capture that some shocks may be less persistent that others. In the literature, it is common to include two independent processes, one that captures permanent or highly persistent shocks and another that captures more transitory shocks. Additional and independent processes could also be included to capture measurement errors in earnings. For our purposes, it is sufficient to recognize that the effects of such additional and independent processes on earnings can be accounted for by including additional MA and/or a suitable number of AR terms in equation (3), and this way of specifying the earnings process will not affect our identification of a unit root in the data generating process for earnings (that is, the properties of the largest AR root). ${ }^{7}$ To keep the discussion simple, we disregard such additional terms for now and discuss them in connection to our empirical specification in the next sub-section.

Based on the model in equations (2) and (3), the focus in this paper is whether $\rho$ is equal to or smaller than unity and this has been addressed in a number of different ways in the literature. In an influential paper based on the autocovariance structure of labor-income data for the United States, MaCurdy (1982) is unable to reject $\rho=1$ as well as $\psi^{i}=0$ for all $i$ in equation (2); hence, individuals' relative earnings are nonstationary (without a drift). These properties have also found much support in individual consumption data and are used in most calibrations of life-cycle models. Not all studies based on the autocovariance structure find support for the UR model though. In particular, Baker (1997) and Guvenen (2009) have relied on so called 'covariance models' in order to discriminate between processes. Here, the implied expressions for variances and autocovariances implied by models such as in equation (2) are fitted to the empirical counterpart by minimum distance estimation. Both these studies have found estimates of $\rho$ that are statistically and economically significantly well below unity while instead $\psi^{i} \neq 0$ and $\delta^{i} \neq 0$ for at least one $i$. That is, individual earnings are trend

\footnotetext{
${ }^{7}$ The properties of any invertible MA processes can be captured by a suitable AR process. For this, as well as details on how several independent processes can be captured in a single process, see, for example, Hamilton (1994).
} 
stationary. This is also the property of the labor income process that Guvenen (2007) finds support for based on US consumption data.

\subsection{Empirical strategy}

In this paper we will approach the question of $\rho$ 's value using a methodology that has not been employed previously in this field, namely the local-to-unity framework. ${ }^{8}$ This takes its starting point in the near-integrated process. A near-integrated process is one that has an AR root close to unity which means that it in finite samples bears many similarities to a unit-root process. In its simplest form, this is given by

$x_{t}=\phi x_{t-1}+\eta_{t}$,

where

$\phi=1+c / T$,

$\eta_{t}$ is an iid error term, $c$ is the local-to-unity parameter and $T$ is the sample size. The local-tounity parameter can hence be seen as measuring the autoregressive root's deviation from unity relative to the length of the sample. When $c=0$, the autoregressive root is unity. Using the terminology of Phillips (1987, 1988), $c<0$ means that the process is "strongly autoregressive" - but mean reverting - whereas the process is "mildly explosive" if $c>0$. In practice, economists are almost exclusively interested in whether $c=0$ or $c<0$ and this study does not constitute an exception.

The typical focus when time series are analyzed is whether the null hypothesis of a unit root can be rejected or not, even though it is well known that tests of the Dickey-Fuller variety tend to have low power against local alternatives. ${ }^{9}$ As pointed out by Andrews (1993, p. 139):

\footnotetext{
${ }^{8}$ Analysis based on the local-to-unity framework has become increasingly popular, with applications commonly found in macroeconomics and finance; see, for example, Cavanagh et al. (1995), Lanne (2000), Campbell and Yogo (2006) and Beechey et al. (2009).

${ }^{9}$ A vast majority of unit-root tests have a unit root under the null hypothesis, including the two tests that probably are the most commonly used, namely the Augmented Dickey-Fuller test (Said and Dickey, 1984) and the Augmented Dickey-Fuller test with GLS detrending (Elliot et al., 1996). The KPSS test (Kwiatkowski et al.,
} 
"In such cases, the failure to reject the null hypothesis cannot be constructed as providing evidence in favor of the null'. In fact, in the application in this paper, each estimate of the largest autoregressive root could be substantially different from unity but the null of a standard unit-root test might still not be rejected. We follow workers' earnings over a maximum of 37 years, which is as far as we can go without running into data problems associated with early retirement later in life and schooling early in life. Since the data are annual, the number of observations is limited and the power of Dickey-Fuller type unit-root tests can accordingly not be expected to be very high.

The local-to-unity framework provides a means to address the question of a unit root in worker's data generating process for earnings while at the same time circumventing the issue of poor power in unit-root tests. The approach has a number of advantages. First, it allows us to address the downward bias of the OLS estimator of $\phi$ in equation (4) by obtaining median unbiased estimates of $c .^{10}$ Second, with a large number of median unbiased estimates we can focus on empirical distributions of the local-to-unity parameter, $c$; with a total of 2,486 observations, such distributions provide a large amount of information regarding the presence of a unit root in earnings. Of specific interest is the location of the median of the estimated local-to-unity parameters; if the UR model is indeed a correct characterization of workers' earnings processes, this median is expected to be located at or close to zero.

The process underlying the empirical models used in this paper is more general than equation (4) in that both deterministic terms and a richer dynamic structure - namely a general $\operatorname{ARMA}(p, q)-$ are allowed for. ${ }^{11}$ More specifically, it is given by

$x_{t}=\mu+\theta t+v_{t}$,

where

$\kappa(L) v_{t}=\omega_{t}$.

1992) provides an important exception but also suffers from poor power properties and is less frequently employed in empirical work.

${ }^{10}$ It is a well-known fact that while the OLS estimate of $\phi$ is consistent, it is biased. The bias is present not only AR(1) models but also in AR( $p$ ) models; see, for example, Shaman and Stine (1988) for a discussion.

${ }^{11}$ Recall that an AR process of appropriate order can approximate a general $\operatorname{ARMA}(p, q)$ process; see also footnote 7 . 
$\omega_{t}$ is an iid error term and $\kappa(L)=\chi(L)(1-\rho L)$, where $\chi(L)=\sum_{j=0}^{m-1} \chi_{j} L^{j}$ and $\chi_{0}=1 . \kappa(L)$ is hence factorized such that the largest root, $\rho=1+c / T$, is distinguished from the fixed stable roots.

The median unbiased estimate of $c$ is obtained by employing a method suggested by Stock (1991) which is straightforward to carry out. A unit-root test statistic - in our case we rely on the test statistic from the ADF test with GLS detrending (henceforth ADF-GLS test) of Elliot et al. (1996) - is calculated based on data. This is simply the $t$-statistic on $\hat{\gamma}$ in equation (8) below:

$$
\Delta \tilde{r}_{t}^{i}=\gamma \tilde{r}_{t-1}^{i}+\sum_{j=1}^{m} \lambda_{i} \Delta \tilde{r}_{t-j}^{i}+\varepsilon_{t},
$$

where $\tilde{r}_{t}^{i}$ is the GLS-detrended value of $r_{t}^{i}$, where $r_{t}^{i}$ is calculated as in equation (1). In the GLS detrending, we focus on the case where we allow each individual to have both a constant and a trend; in the analysis, we do, however, also present estimates where we only allow for a constant. ${ }^{12}$ Using the known distribution of the test statistic under the alternative hypothesis, this statistic then maps to a median unbiased estimate of $c$; see Stock (1991) and Campbell and Yogo (2006) for details. ${ }^{13}$ This estimate of $c$ could in turn be used to calculate an estimate of the largest autoregressive root, $\rho$. However, seeing that (for a given $T$ ) there is a one-toone mapping between $c$ and $\rho$, we choose to focus on $c .{ }^{14}$

\footnotetext{
${ }^{12}$ Since equation (8) is estimated separately for each individual, each individual is allowed to have a unique empirical data generating process. The lag length in each test equation is determined using the Schwarz (1978) information criterion.

${ }^{13}$ In practice, the distribution of the test statistic is simulated for a large number of $c$ :s. The $c$ which has the observed value of the test statistic as its median value is the value of $c$ that is the median unbiased estimate.

${ }^{14}$ As a comparison to our applied local-to-unity framework, we in Appendix B also present and discuss results from a traditional unit-root test analysis based on applying the ADF-GLS test to each series.
} 


\section{Initial analysis using a traditional autocovariance method}

Since the analysis in our paper utilizes Swedish labor-income data, it is relevant to ask what the Swedish autocovariance structure of earnings implies in terms of individual's earnings processes. Like for the US, the evidence turns out to be mixed. In Appendix C, we present an analysis of the autocovariance structure of earnings for our sample of a Swedish birth-cohort along the lines of MaCurdy (1982). Similar to the studies that use this approach on US data, the main conclusion from this exercise is that autocovariances support a nonstationary process. However, as discussed in the introduction to this paper, studies such as Baker (1997) and Guvenen (2009) have highlighted several, potentially severe, statistical difficulties with this approach. Consistent with this, not all our applied statistical tests are supportive of the UR-model.

\section{Results from the local-to-unity analysis}

The results from the local-to-unity analysis for each education group - where equation (8) has been employed to data that were GLS detrended using both a constant and a trend - are depicted in Figures 1 to 3 and in Table $1 .{ }^{15}$ The distributions of the estimated local-to-unity parameters show strong similarities across education groups with the great mass of the distribution located well below zero.

With values notably below zero, the medians of the estimated local-to-unity parameters indicate than the UR model is not a correct characterization of the typical earnings process. For the three education groups, the median estimates range from -9.8 to -8.2 ; see Table 1 . To put these numbers into perspective, it can be noted that the median estimate for those with a high-school education, which is $c=-9.2$, corresponds to the largest autoregressive root being 0.75. For an $\mathrm{AR}(1)$ process with a persistence of 0.75 , the half life of a shock - that is, the time it takes for half of the effect of the shock to vanish - is approximately 2.4 years; after six years, roughly 18 percent of the effect still remains. This stands in sharp contrast to the UR model, where the half life of a shock is infinity (that is, shocks have a permanent effect). From an economic perspective, it should be noted that even if the unit root does not find support, shocks have an effect that is non-negligible also at reasonably long horizons.

\footnotetext{
${ }^{15}$ Note that in all figures, the bar furthest to the left contains all observations smaller than the value in question.
} 
A relevant question to ask is whether the median estimates of $c$ also are statistically significantly different from zero. We have investigated this through a bootstrap procedure which is conducted separately for each education group, $j$. Initially, we randomly sample $n_{j}$ individuals with replacement and estimate the local-to-unity parameter for each individual. ( $n_{j}$ is equal to the sample sizes originally used for each group, that is, 741 for those with a primary-school education, 1,078 for those with a high-school education and 667 for the college educated.) We then calculate the median of these estimates. This procedure is repeated 10,000 times and we accordingly get 10,000 estimates of the median of the estimated local-tounity parameters. The values corresponding to the 2.5th and 97.5th percentiles in our distributions of median estimates are shown in Table 1, thus giving a 95\% confidence interval. As can be seen, the median estimates of $c$ are significantly different from zero. In fact, none of the bootstrap estimates of the median are above zero.

Figure 1. Estimated local-to-unity parameter for individuals with primary-school education.

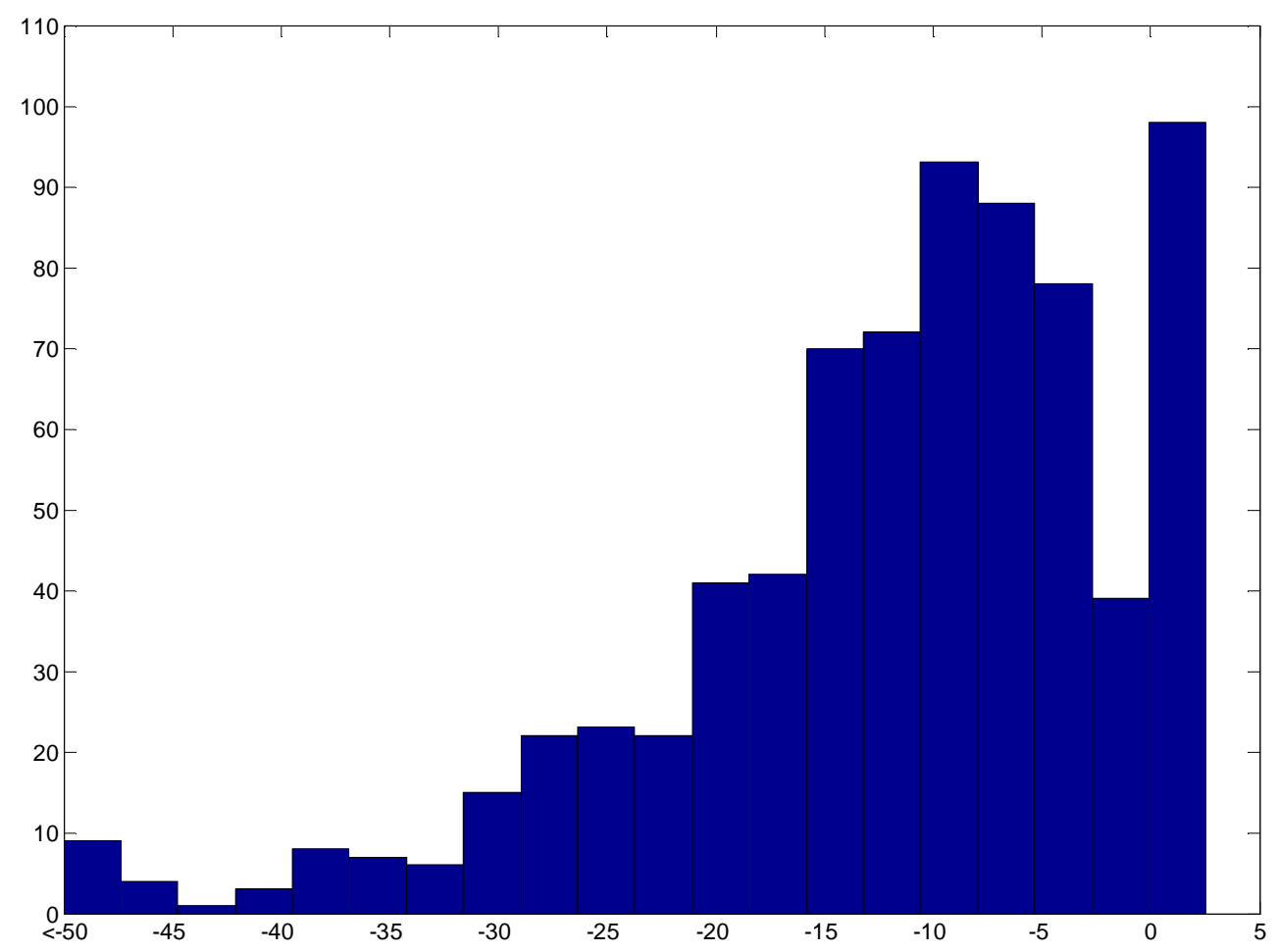

Note: GLS detrending conducted with constant and trend. 
Figure 2. Estimated local-to-unity parameter for individuals with high-school education.

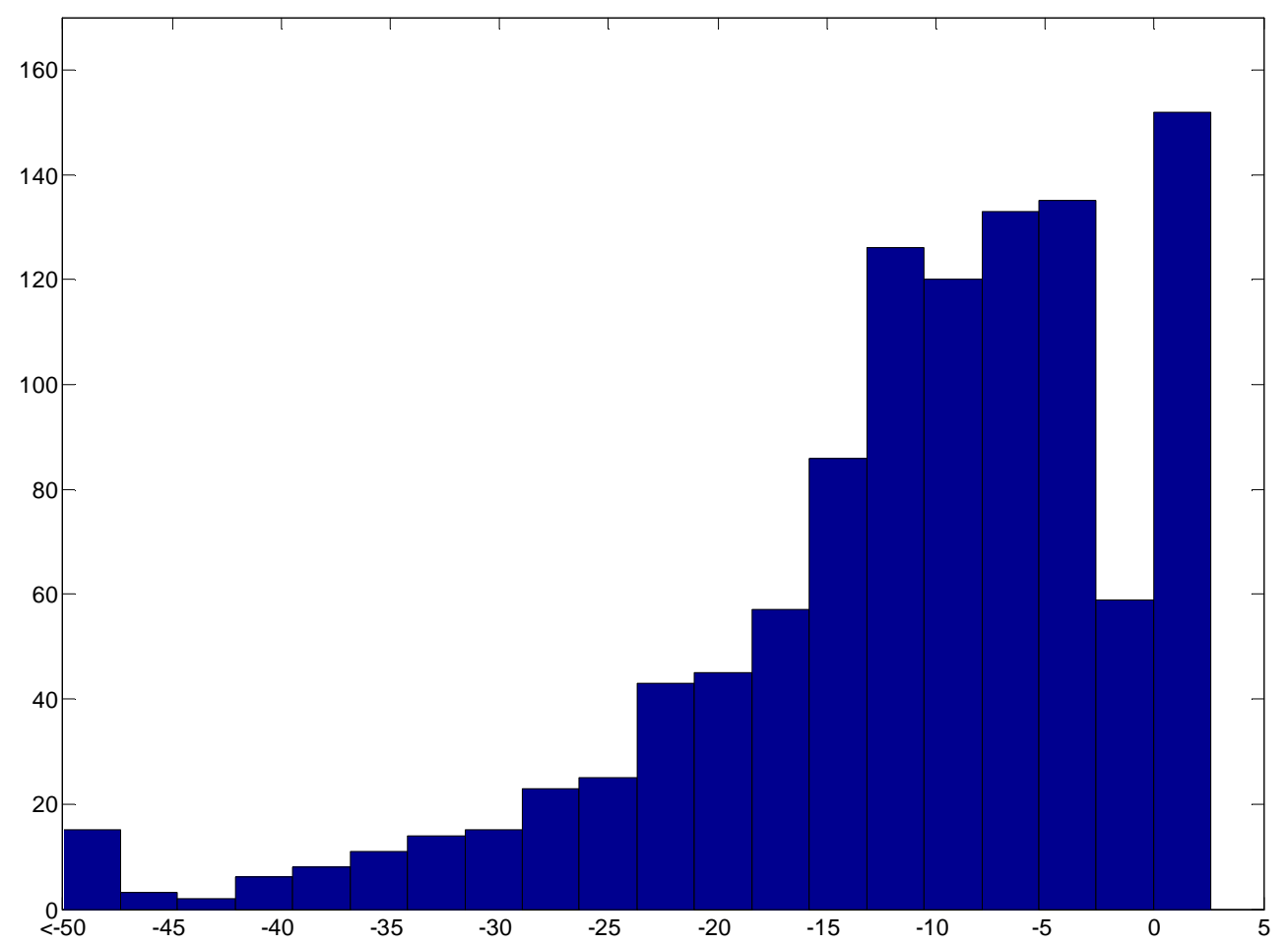

Note: GLS detrending conducted with constant and trend.

Figure 3. Estimated local-to-unity parameter for individuals with college education.

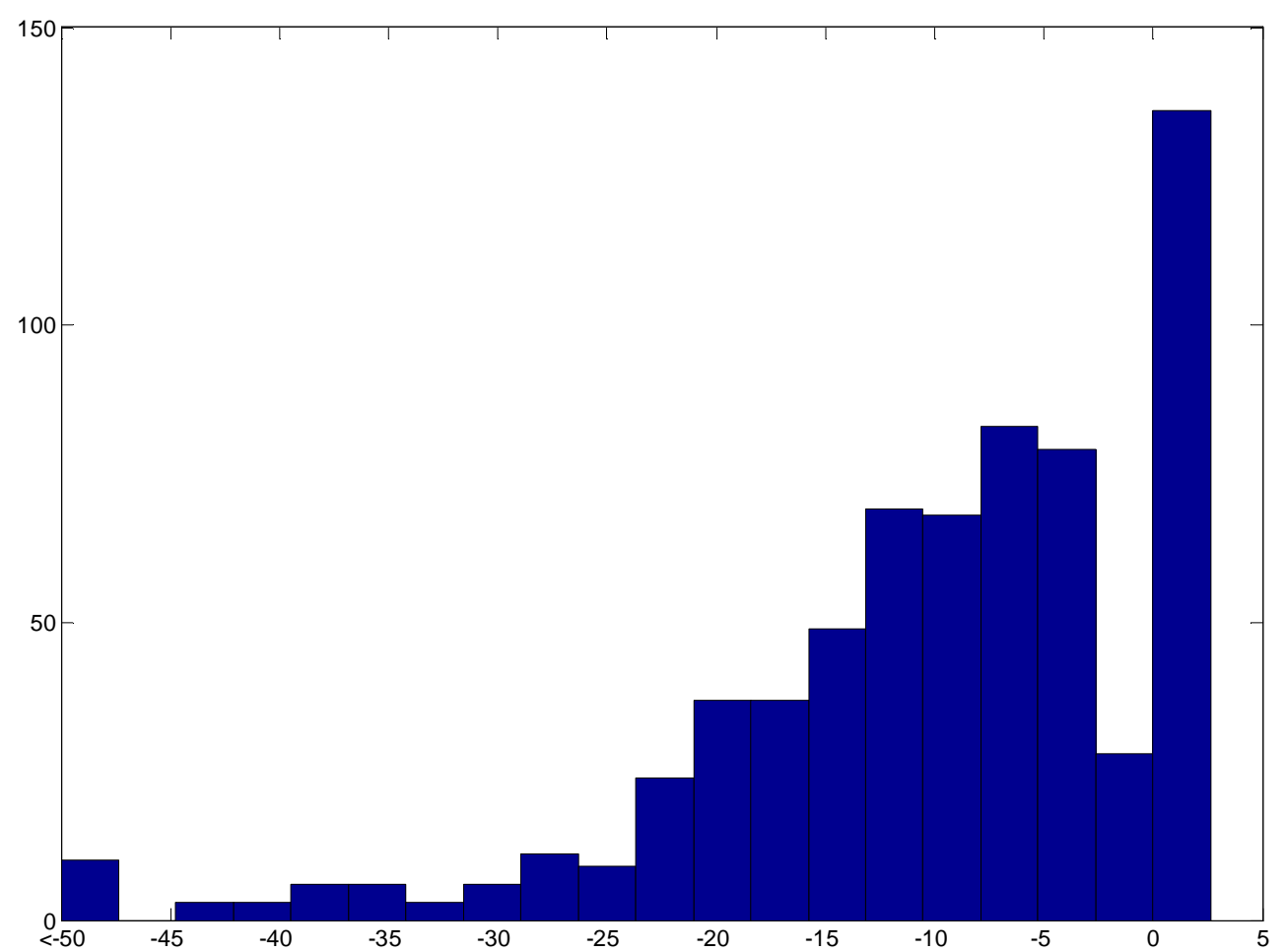

Note: GLS detrending conducted with constant and trend. 
Table 1. Results from local-to-unity analysis.

\begin{tabular}{|c|c|c|c|c|c|c|}
\hline & \multicolumn{3}{|c|}{ With individual-specific trends } & \multicolumn{3}{|c|}{ Without individual-specific trends } \\
\hline & Primary & High school & College & Primary & High school & College \\
\hline Median $\hat{c}$ & -9.8 & -9.2 & -8.2 & -5.0 & -4.7 & -4.2 \\
\hline $\begin{array}{l}\text { Implied largest } \\
\text { AR root }\end{array}$ & 0.73 & 0.75 & 0.74 & 0.87 & 0.87 & 0.87 \\
\hline $\begin{array}{l}\text { Bootstrapped } \\
95 \% \text { confidence } \\
\text { interval for } \\
\text { median } \hat{c}\end{array}$ & {$[-10.6,-9.1]$} & {$[-9.9,-8.4]$} & {$[-9.0,-7.5]$} & {$[-5.9,-4.4]$} & {$[-5.2,-4.3]$} & {$[-4.8,-3.5]$} \\
\hline Share with $\hat{c} \geq 0$ & $13 \%$ & $14 \%$ & $14 \%$ & $12 \%$ & $13 \%$ & $12 \%$ \\
\hline Std. dev. $\hat{c}$ & 12.2 & 14.0 & 13.1 & 9.1 & 8.8 & 10.9 \\
\hline $\mathrm{P} 10 \hat{c}$ & -26.5 & -24.7 & -23.0 & -18.0 & -16.9 & -14.4 \\
\hline $\mathrm{P} 90 \hat{c}$ & 1.7 & 1.7 & 1.9 & 0.2 & 0.4 & 0.1 \\
\hline
\end{tabular}

Note: "P10 $\hat{c}$ " and "P90 $\hat{c}$ " are the values of $\hat{c}$ corresponding to the 10th and 90th percentiles respectively from the distributions in question.

What do our results imply concerning a unit root in earnings for individuals with large estimates of $c$ ? The answer depends on the assumptions one is willing to make. If one takes the stand that the size of the largest autoregressive root is the same, or similar for all individuals - along the spirit of the assumptions made in most calibrations of life-cycle models and in most test of the UR model based on autocovariances - the median estimate of $c$ suggests that no one has a unit root in earnings. Since the median unbiased estimate has the property that the probability of overestimation is equal to the probability of underestimation, this view suggests that estimates differ from that of the median simply because of random estimation error. If one instead takes the stand that individuals differ significantly in their values of the largest AR root, as for instance argued in Browning et al. (2010), the estimates are consistent with the view that some individuals have a unit root; for all three education groups, approximately 14 percent of the individuals have an estimate of $c$ that is zero or larger. ${ }^{16}$ However, the median of the estimates of $c$ still implies that earnings for the representative agent - in terms of being the median individual - are trend stationary, and thus are governed by a process which features shocks with temporary rather than permanent effects.

\footnotetext{
${ }^{16}$ Browning et al. (2010) allow the entire income process to be heterogeneous across individuals through the use of a simulation based method known as 'simulated minimum distance', which utilizes the auto-covariance structure of earnings.
} 
The results in Figures 1 to 3 are generated under the assumption that individuals may have individual-specific trends. However, some applications of the UR model do not allow for such trends. It is therefore interesting to see how our results change once we impose the restriction that no one has individual-specific trends in their data generating process. As expected, excluding the trends leads to higher median estimates of $c$, now being roughly half of their previous negative value. The bootstrapped confidence intervals nevertheless clearly show that the median estimate of $c$ is significantly different from zero for all three education groups; see Table 1. Translated into the largest autoregressive root, the median estimates now imply a value of 0.87 for all three education groups. However, the share of individuals with an estimate of $c$ below zero - implying a mean-reverting process - actually increases marginally. This may seem odd at first. However, the exclusion of the individual-specific trends reduces the dispersion of the whole distributions for $c$; Table 1 displays a marked fall in the standard deviations and increases in the lowest 10th percentile of the estimates. That is, the share of individuals with very negative estimates of $c$ also falls. This might partly be explained by the fact that we may incorrectly have included individual-specific trends for some individuals; inclusion of irrelevant variables is well known to lead to more imprecise estimates. In addition, Stock (1991) shows that the precision in the estimates increases as $c$ gets larger. The distributions are however still strongly skewed to the left, away from the unit root; see Figures D1 to D3 in Appendix D. To conclude, our results imply higher persistence in labor-income shocks for the representative workers once we discard individual-specific trends, but there is still no evidence in favor of a 'pure' unit root.

\section{Conclusions}

This paper investigates the presence of a unit root in individual earnings by applying direct time-series methods that previously have not been employed in the literature. Using a registerbased longitudinal dataset which allows us to follow a cohort of workers from 1968 to 2005, we are able to obtain empirical distributions of median unbiased estimates of local-to-unity parameters. These distributions indicate that earnings for the majority of workers in our sample are governed by a trend- (or mean-) reverting process.

Many life-cycle or overlapping generations models are currently calibrated using a laborincome process where earnings for the representative individual are governed by a unit-root process, that is, shocks to earnings have permanent effects. The previous empirical evidence 
in favor of such a specification is mixed though. This paper has investigated the issue of a unit root in a new way and our results clearly question the heavy use of unit-root processes for earnings. Our findings are hence in line with those favoring transitory rather than permanent effects of shocks to earnings, such as Baker (1997), Guvenen (2009) and Browning et al. (2010). Our results are thereby also consistent with labor-income processes that imply less uncertainty about future earnings than what is commonly assumed, along the lines of those suggested by Guvenen (2007) and Guvenen and Smith (2010). 


\section{References}

Abowd, J. and D. Card (1989), "On the Covariance Structure of Earnings and Hours Changes", Econometrica 57, 411-445.

Andrews, D. W. K. (1993), "Exactly Median-Unbiased Estimation of First Order Autoregressive/Unit Root Models", Econometrica 61, 139-165.

Atkinson, A., F. Bourguignon and C. Morrisson (1992), Empirical Studies of Earnings Mobiltiy, Harwood Academic Publishers, Philadelphia.

Baker, M. (1997), "Growth-Rate Heterogeneity and the Covariance Structure of Earnings", Journal of Labor Economics 15, 338-375.

Baker, M. and G. Solon (2003), "Earnings Dynamics and Inequality among Canadian Men, 1976-1992: Evidence from Longitudinal Tax Records", Journal of Labor Economics 21, 267-288.

Beechey, M., E. Hjalmarsson, and P. Österholm (2009), "Testing the Expectations Hypothesis when Interest Rates Are Near Integrated”, Journal of Banking and Finance 33, 934-943.

Browning, M., M. Ejrnæs and J. Alvarez (2010), "Modelling Inomce Processes with Lots of Heterogeneity", Review of Economic Studies 77, 1353-1381.

Campbell, J. Y. and M. Yogo (2006), "Efficient Tests of Stock Return Predictability”, Journal of Financial Economics 81, 27-60.

Carroll, C. (1992), "The Buffer-Stock Theory of Saving: Some Macroeconomic Evidence", Brookings Papers on Economic Activity 2, 61-135.

Carroll, C. and A. Samwick (1998), "How Important is Precautionary Saving?", Review of Economics and Statistics 80, 410-419.

Cavanagh, C. L., G. Elliott and J. H. Stock (1995), "Inference in Models with Nearly Integrated Regressors", Econometric Theory 11, 1131-1147.

Davis, S. and P. Willen (2000), "Occupation-Level Income Shocks and Asset Returns: Their Covariance and Implications for Portfolio Choice”, CRSP Working Paper No. 532.

Deaton, A. and C. Paxson (1994), "Intertemporal Choice and Inequality", Journal of Political Economy 102, 384-394

Edin, P.-A. and P. Fredriksson (2000), "LINDA - Longitudinal Individual Data for Sweden" Working Paper 2000:19, Department of Economics, Uppsala University.

Elliott, G., T. J. Rothenberg and J. H. Stock (1996), "Efficient Tests for an Autoregressive Unit Root", Econometrica 64, 813.836.

Evans, G. B. A. and N. E. Savin (1981), “Testing for Unit Roots: 1”, Econometrica 49, 753779 . 
Evans, G. B. A. and N. E. Savin (1981), "Testing for Unit Roots: 2", Econometrica 52, 12411269.

Fitzgerald, J., P. Gottschalk and R. Moffitt (1998), “An Analysis of Sample Attrition in Panel Data: The Michigan Study of Income Dynamics", Journal of Human Resources 33, 251-299.

Gourinchas, P-O and J.Parker (2002), "Consumption over the Life Cycle." Econometrica 70, 47-89.

Guvenen, F. (2007), "Learning Your Earnings: Are Labor Income Shocks Really Very Persistent?", American Economic Review 97, 687-712.

Guvenen, F. (2009), “An Empirical Investigation of Labor Income Processes", Review of Economic Dynamics 12, 58-79.

Guvenen, F. and A. Smith (2010), "Inferring Labor Income Risk From Economic Choices: An Indirect Inference Approach”, NBER Working Paper No. 16327.

Haider, J. (2001), "Earnings Instability and Earnings Inequality of Males in the United States: 1967-1991”, Journal of Labor Economics 19, 799-836.

Hamilton, J. D. (1994), Time Series Analysis, Princeton University Press, Princeton.

Kimball, M. (1990), "Precautionary Saving in the Small and in the Large", Econometrica 58, $53-73$.

Kwiatkowski, D., P. C. B. Phillips, P. Schmidt and Y. Shin (1992), "Testing the Null Hypothesis of Stationarity Against the Alternative of a Unit Root: How Sure are We That Economic Time Series Have a Unit Root?", Journal of Econometrics 54, 159-178.

Lanne, M. (2000), "Near Unit Roots, Cointegration, and the Term Structure of Interest Rates", Journal of Applied Econometrics 15, 513-529.

Low, H. (2005), "Self-Insurance in a Life-Cycle Model of Labour Supply and Savings", Review of Economic Dynamics 8, 945-975.

Lucas, R. (2003), “Macroeconomic Priorities”, American Economic Review 93, 1-14.

MaCurdy, T. (1982), "The Use of Time Series Processes to Model the Error Structure of Earnings in Longitudinal Data Analysis", Journal of Econometrics 18, 83-114.

Maddala, G. S. and I.-M. Kim (1998), Unit Roots, Cointegration, and Structural Change, Cambridge University Press, Cambridge.

Mincer, J. (1974), Schooling, Experience and Earnings, Columbia University Press, New York. 
Meghir, C. and L. Pistaferri (2004), "Income Variance Dynamics and Heterogeneity", Econometrica 72, 1-32.

Meghir, C. and L. Pistaferri (2010), "Earnings, Consumption and Lifecycle Choices”, NBER Working Paper No. 15914.

Moffitt, R. and P. Gottschalk (2002), "Trends in the Transitory Variance of Earnings in the United States", Economic Journal 112, 68-73.

Neal, D. and S. Rosen (2000), "Theories of the Distribution of Earnings", in A. Atkinson and F. Bourguignon (eds.), Handbook of Income Distribution, Vol. 1, Elsevier Science B.V., Amsterdam.

Palme, M. (1995), "Earnings Mobility and Distribution: Comparing Statistical Models on Swedish Data", Labour Economics 2, 213-247.

Phillips, P. C. B. (1987), “Towards a Unified Asymptotic Theory for Autoregression”, Biometrica 74, 535-547.

Phillips, P. C. B. (1988), "Regression Theory for Near-Integrated Time Series", Econometrica $56,1021-1043$.

Said, S. E. and D. A. Dickey (1984), "Testing for Unit Roots in Autoregressive Moving Average Models of Unknown Order", Biometrika 71, 599-607.

Schwarz, G. (1978), "Estimating the Dimension of a Model”, Annals of Statistics 6, 461-464.

Shaman, P. and Stine, R. A. (1988), "The Bias of Autoregressive Coefficient Estimators", Journal of the American Statistical Association 83, 842-848.

Stock, J. H. (1991), "Confidence Intervals for the Largest Autoregressive Root in U.S. Economic Time-Series“, Journal of Monetary Economics 28, 435.460.

Storesletten, K., C. Telmer, and A. Yaron (2004), "Consumption and Risk Sharing Over the Life Cycle", Journal of Monetary Economics 51, 609-633.

Topel, R. and M. Ward (1992), "Job Mobility and the Careers of Young Men”, Quarterly Journal of Economics 107, 439-479.

Zivot, E. and J. Wang (2006), Modeling Financial Time Series with S-Plus, Springer, New York. 


\section{Appendix A. Selected time series graphs of relative earnings}

Figure A1. Time series of $r_{t}^{i}$ for selected individuals with a high-school education.
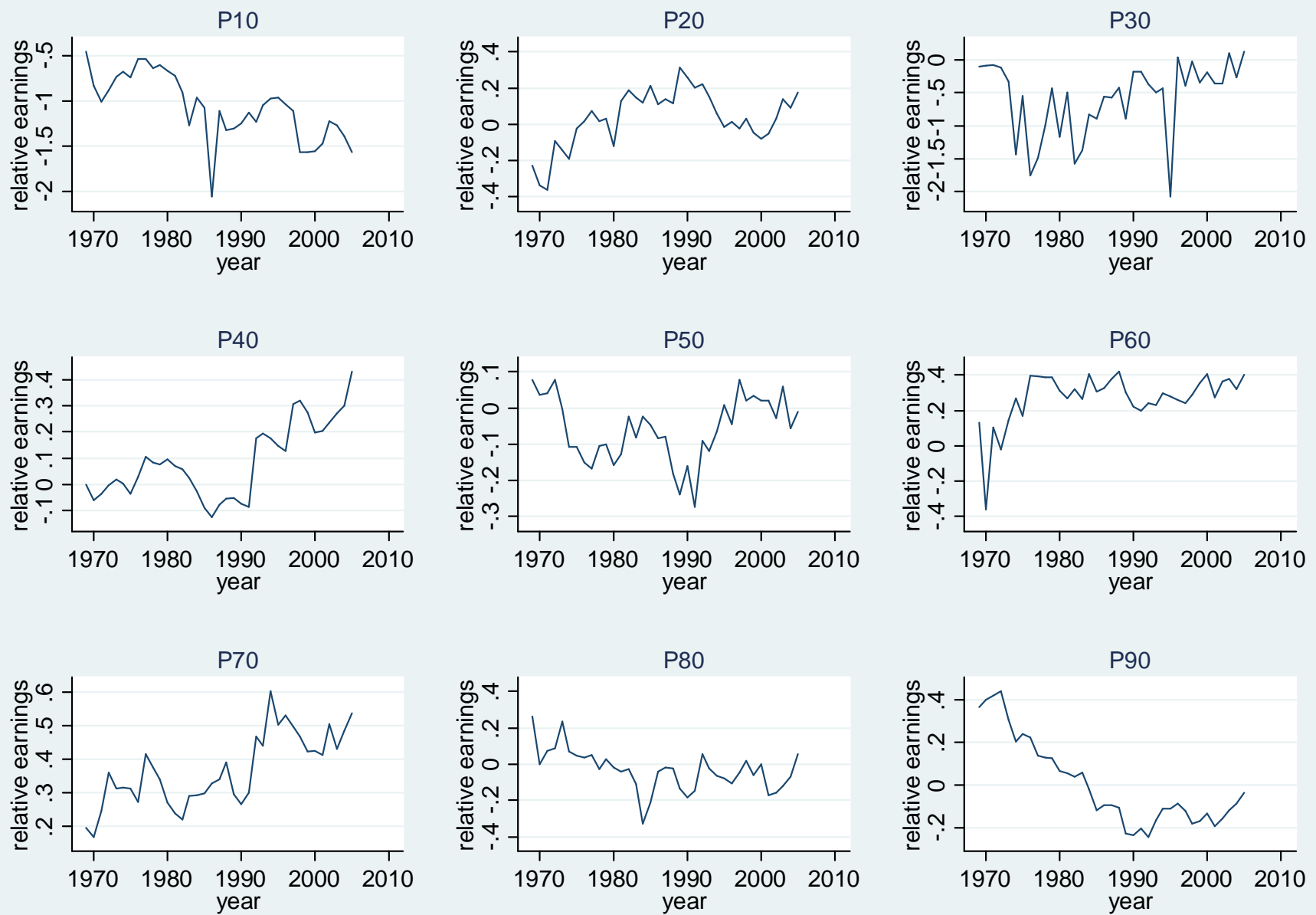

Note: P10 means that the individual is located at the 10th percentile in the earnings distribution for high-school educated individuals in the first year. 


\section{Appendix B. Results from ADF-GLS unit-root tests}

In this appendix, we report the share of tests where the null hypothesis of the ADF-GLS test is rejected. As can be seen from Table B1, the null of a unit root is rejected between 18 and 22 percent of the time for the three education groups when allowing for both a constant and a trend. Allowing for only a constant, the null is rejected between 31 and 40 percent of the time. This inability to reject a unit root would perhaps, per se, by some be interpreted as providing evidence in favor of the UR model; the results from the local-to-unity analysis clearly question this conclusion though. This illustrates the problem of relying on traditional unit-root tests for the question analyzed in this study.

Table B1. Fraction where the null hypothesis of the ADF-GLS test is rejected.

\begin{tabular}{lccc}
\hline & Primary school & High school & College \\
\hline Constant & $40 \%$ & $37 \%$ & $31 \%$ \\
Constant and trend & $22 \%$ & $20 \%$ & $18 \%$ \\
\hline
\end{tabular}

Notes: Significance level used is five percent. "Constant" indicates that GLS detrending was conducted with constant only; "Constant and trend" indicates that GLS detrending was conducted with constant and trend. 


\section{Appendix C. Tests based on the autocovariance structure of first-differenced earnings.}

In this appendix we investigate the presence of a unit root in individual earnings by studying the autocovariance structure of first-differenced earnings along the lines pioneered by MaCurdy (1982). We also briefly recapitulate the main criticism raised against this approach.

Consider first the alternative where individual (relative) earnings follow an AR(1) unit-root process without any deterministic component. In equation (2), this corresponds to $\rho=1$ and $\sigma_{\psi}^{2}=0$. As recognized by MaCurdy (1982), this model implies the testable implication that autocovariances of income changes, $\Delta r_{t}^{i}=r_{t}^{i}-r_{t-1}^{i}$, should be equal to zero at all lags; income changes are driven by idiosyncratic shocks that by definition are uncorrelated. If an MA term is also present in the income process, autocovariances should be different from zero (generally negative) at the first lag but zero at all higher lags. Adding two MA terms makes the two lowest lags different from zero, and so forth. If we in equation (2) instead have $0<\rho<1$ and $\sigma_{\psi}^{2} \neq 0$, it can be shown that higher order autocovariances of income changes should be positive; see Guvenen (2009) for a detailed exposition.

Following such studies as MaCurdy (1982), Abowd and Card (1989), Topel and Ward (1992), and Meghir and Pistaferri (2004), Table C1 presents average autocovariances of income changes with accompanied standard errors for the first 20 lags. Similar to the results in these US studies, average autocovariances are all insignificantly different from zero for all education groups (also for the even longer lags not shown in Table C1). Within the framework of equation (2), this pattern is consistent with an income process where $\rho=1$ and $\sigma_{\psi}^{2}=0$. Hence, like for the US, the MaCurdy (1982) approach supports a UR model for Swedish data

Two serious objections have however been raised against the above approach. Firstly, Baker (1997) shows, based on Monte Carlo analysis, that the employed statistical test has poor power in finite samples, so that it is hard to reject the null of covariances equal to zero. Or in Baker's (1997, p. 364) own words: “Clearly this test cannot provide reliable evidence against the alternative of person-specific profiles". Secondly, and also based on Monte Carlo analysis, Guvenen (2009) shows that if $\rho$ is sufficiently large, albeit still allowed to be substantially 
lower than unity, and $\sigma_{\psi}^{2}$ is quantitative small, albeit still economically significant in terms of affecting the dispersion of life-cycle earnings, and there also is noise in the data, it becomes even harder to find evidence in favor of (the true) trend-stationary process.

One way to try and validate the above analysis might be to use a Wald-test to investigate if all covariances above a certain lag are jointly equal to zero, as for instance done in Abowd and Card (1989). Based on the results in Table C1, a reasonable strategy for our data is to test the autocovariances above the first order, since the first order covariances are close to being statistically significant. As it turns out, we are actually able to reject the null of all autocovariances beyond the first lag jointly being equal to zero for all education groups (teststatistics not shown but available on request). We are also able to reject that auto-covariances above the fifth and tenth order are jointly equal to zero, respectively. These results contradict the above support for the UR model. They are also similar to the US evidence in Baker (1997), as he also finds support for the UR model when single restrictions on the autocovariance matrix are tested but not when joint restrictions are tested. However, there is also serious criticism against this particular test. Baker (1997) demonstrates that it has inflated size in small samples. Guvenen (2009) also highlights that results from this joint test are not straightforward to translate into evidence for a certain income process - either a stationary or nonstationary - since it does not distinguish between positive and negative deviations from zero.

Since autocovariances can be sensitive to outliers, we have also performed the above analysis with samples where individuals are required to have annual earnings above the 'basic amount' - 39,400 in real SEK in 2005 which translates to around 5,000 USD or 4,000 Euro. Conclusions are robust to this alternative sample construction and the only change is that oneby-one tests of autocovariances (as in Table C1) now also indicates the presence of a negative MA term in the earnings processes (results are available on request).

To conclude, like the US studies that employ the MaCurdy (1982) approach, we find evidence in favor of the UR model. However, consistent with the skepticism raised against this methodology, we - like the US study by Baker (1997) - are left with inconclusive evidence once results from joint statistical tests are added to the picture. 
Table C1. Average auto-covariances of first-differenced earnings by education group (std. errors).

\begin{tabular}{|c|c|c|c|}
\hline Auto-covariances & Primary & High-School & College \\
\hline $\operatorname{cov}\left(\Delta r_{t}, \Delta r_{t}\right)$ & $\begin{array}{c}.11011 \\
(.03315)\end{array}$ & $\begin{array}{c}.10933 \\
(.02664)\end{array}$ & $\begin{array}{c}.12553 \\
(.03860)\end{array}$ \\
\hline $\operatorname{cov}\left(\Delta r_{t}, \Delta r_{t-1}\right)$ & $\begin{array}{l}-.03088 \\
(.02021)\end{array}$ & $\begin{array}{l}-.03134 \\
(.01679)\end{array}$ & $\begin{array}{c}-.02317 \\
(.02043)\end{array}$ \\
\hline $\operatorname{cov}\left(\Delta r_{t}, \Delta r_{t-2}\right)$ & $\begin{array}{l}-.00765 \\
(.01001)\end{array}$ & $\begin{array}{l}-.00540 \\
(.00810)\end{array}$ & $\begin{array}{l}-.01375 \\
(.01326)\end{array}$ \\
\hline $\operatorname{cov}\left(\Delta r_{t}, \Delta r_{t-3}\right)$ & $\begin{array}{l}-.00384 \\
(.00792)\end{array}$ & $\begin{array}{l}-.00356 \\
(.00601)\end{array}$ & $\begin{array}{c}-.00138 \\
(.01137)\end{array}$ \\
\hline $\operatorname{cov}\left(\Delta r_{t}, \Delta r_{t-4}\right)$ & $\begin{array}{l}-.00105 \\
(.00698)\end{array}$ & $\begin{array}{l}-.00318 \\
(.00537)\end{array}$ & $\begin{array}{c}-.00234 \\
(.00964)\end{array}$ \\
\hline $\operatorname{cov}\left(\Delta r_{t}, \Delta r_{t-5}\right)$ & $\begin{array}{c}-.00245 \\
(.00611)\end{array}$ & $\begin{array}{c}.00085 \\
(.00483)\end{array}$ & $\begin{array}{c}-.00493 \\
(.00874)\end{array}$ \\
\hline $\operatorname{cov}\left(\Delta r_{t}, \Delta r_{t-6}\right)$ & $\begin{array}{c}.00085 \\
(.00592)\end{array}$ & $\begin{array}{l}-.00140 \\
(.00431)\end{array}$ & $\begin{array}{c}.00039 \\
(.00686)\end{array}$ \\
\hline $\operatorname{cov}\left(\Delta r_{t}, \Delta r_{t-7}\right)$ & $\begin{array}{c}.00011 \\
(.00506)\end{array}$ & $\begin{array}{c}.00027 \\
(.00448)\end{array}$ & $\begin{array}{c}-.00001 \\
(.00653)\end{array}$ \\
\hline $\operatorname{cov}\left(\Delta r_{t}, \Delta r_{t-8}\right)$ & $\begin{array}{c}-.00174 \\
(.00501)\end{array}$ & $\begin{array}{l}-.00081 \\
(.00427)\end{array}$ & $\begin{array}{c}.00274 \\
(.00770)\end{array}$ \\
\hline $\operatorname{cov}\left(\Delta r_{t}, \Delta r_{t-9}\right)$ & $\begin{array}{c}.00060 \\
(.00436)\end{array}$ & $\begin{array}{l}-.00155 \\
(.00373)\end{array}$ & $\begin{array}{c}.00021 \\
(.00678)\end{array}$ \\
\hline $\operatorname{cov}\left(\Delta r_{t}, \Delta r_{t-10}\right)$ & $\begin{array}{l}-.00025 \\
(.00438)\end{array}$ & $\begin{array}{c}.00024 \\
(.00366)\end{array}$ & $\begin{array}{l}-.00430 \\
(.00699)\end{array}$ \\
\hline $\operatorname{cov}\left(\Delta r_{t}, \Delta r_{t-11}\right)$ & $\begin{array}{l}-.00105 \\
(.00424)\end{array}$ & $\begin{array}{l}-.00011 \\
(.00351)\end{array}$ & $\begin{array}{c}.00260 \\
(.00656)\end{array}$ \\
\hline $\operatorname{cov}\left(\Delta r_{t}, \Delta r_{t-12}\right)$ & $\begin{array}{c}.00040 \\
(.00413)\end{array}$ & $\begin{array}{l}-.00077 \\
(.00318)\end{array}$ & $\begin{array}{c}-.00010 \\
(.00661)\end{array}$ \\
\hline $\operatorname{cov}\left(\Delta r_{t}, \Delta r_{t-13}\right)$ & $\begin{array}{c}.00022 \\
(.00395)\end{array}$ & $\begin{array}{c}.00106 \\
(.00310)\end{array}$ & $\begin{array}{c}-.00201 \\
(.00692)\end{array}$ \\
\hline $\operatorname{cov}\left(\Delta r_{t}, \Delta r_{t-14}\right)$ & $\begin{array}{c}-.00238 \\
(.00439)\end{array}$ & $\begin{array}{c}-.00131 \\
(.00322)\end{array}$ & $\begin{array}{c}.00257 \\
(.00858)\end{array}$ \\
\hline $\operatorname{cov}\left(\Delta r_{t}, \Delta r_{t-15}\right)$ & $\begin{array}{c}.00210 \\
(.00535)\end{array}$ & $\begin{array}{l}-.00005 \\
(.00384)\end{array}$ & $\begin{array}{c}.00127 \\
(.00932)\end{array}$ \\
\hline $\operatorname{cov}\left(\Delta r_{t}, \Delta r_{t-16}\right)$ & $\begin{array}{c}.00068 \\
(.00491)\end{array}$ & $\begin{array}{c}.00106 \\
(.00431)\end{array}$ & $\begin{array}{l}-.00675 \\
(.00741)\end{array}$ \\
\hline $\operatorname{cov}\left(\Delta r_{t}, \Delta r_{t-17}\right)$ & $\begin{array}{l}-.00280 \\
(.00456)\end{array}$ & $\begin{array}{c}-.00038 \\
(.00357)\end{array}$ & $\begin{array}{c}.00554 \\
(.00622)\end{array}$ \\
\hline $\operatorname{cov}\left(\Delta r_{t}, \Delta r_{t-18}\right)$ & $\begin{array}{c}.00118 \\
(.00406)\end{array}$ & $\begin{array}{c}.00104 \\
(.00337)\end{array}$ & $\begin{array}{c}.00104 \\
(.00630)\end{array}$ \\
\hline $\operatorname{cov}\left(\Delta r_{t}, \Delta r_{t-19}\right)$ & $\begin{array}{l}-.00072 \\
(.00456)\end{array}$ & $\begin{array}{l}-.00003 \\
(.00336)\end{array}$ & $\begin{array}{l}-.00373 \\
(.00489)\end{array}$ \\
\hline $\operatorname{cov}\left(\Delta r_{t}, \Delta r_{t-20}\right)$ & $\begin{array}{c}.00225 \\
(.00451)\end{array}$ & $\begin{array}{l}-.00129 \\
(.00303)\end{array}$ & $\begin{array}{c}-.00027 \\
(.00568)\end{array}$ \\
\hline
\end{tabular}




\section{Appendix D. Estimates without individual-specific trends}

Figure D1. Estimated local-to-unity parameter for individuals with primary-school education.

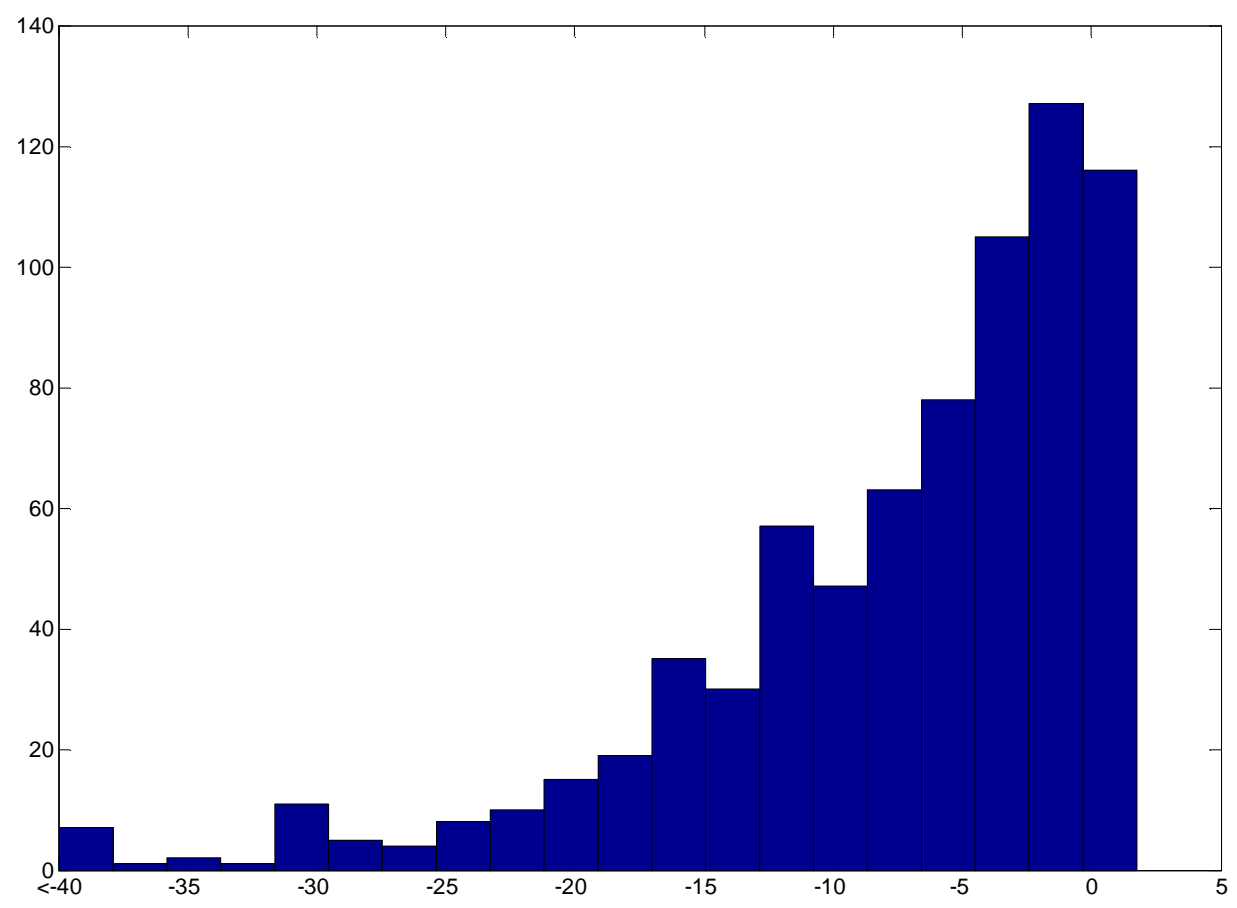

Note: GLS detrending conducted with constant.

Figure D2. Estimated local-to-unity parameter for individuals with high-school education.

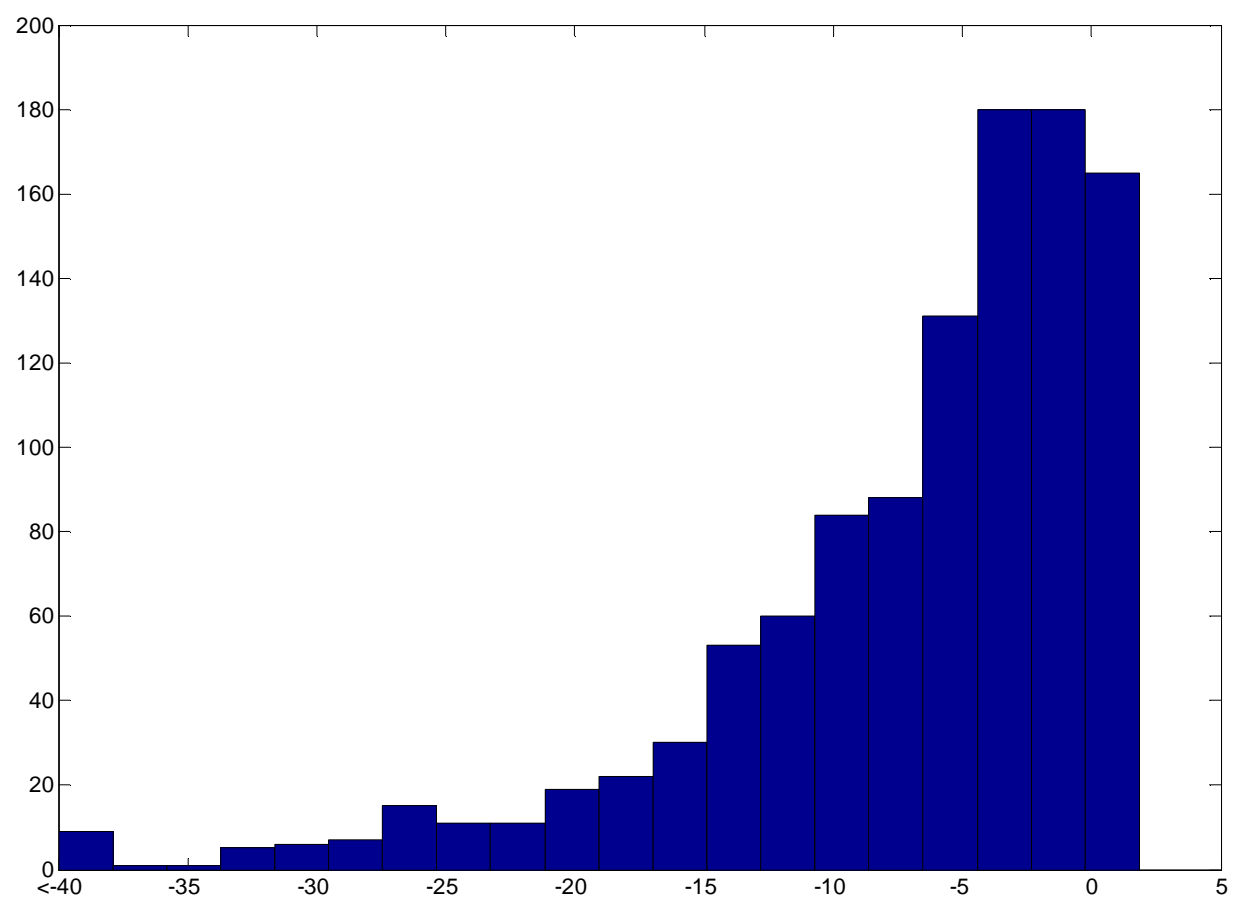

Note: GLS detrending conducted with constant. 
Figure D3. Estimated local-to-unity parameter for individuals with college education.

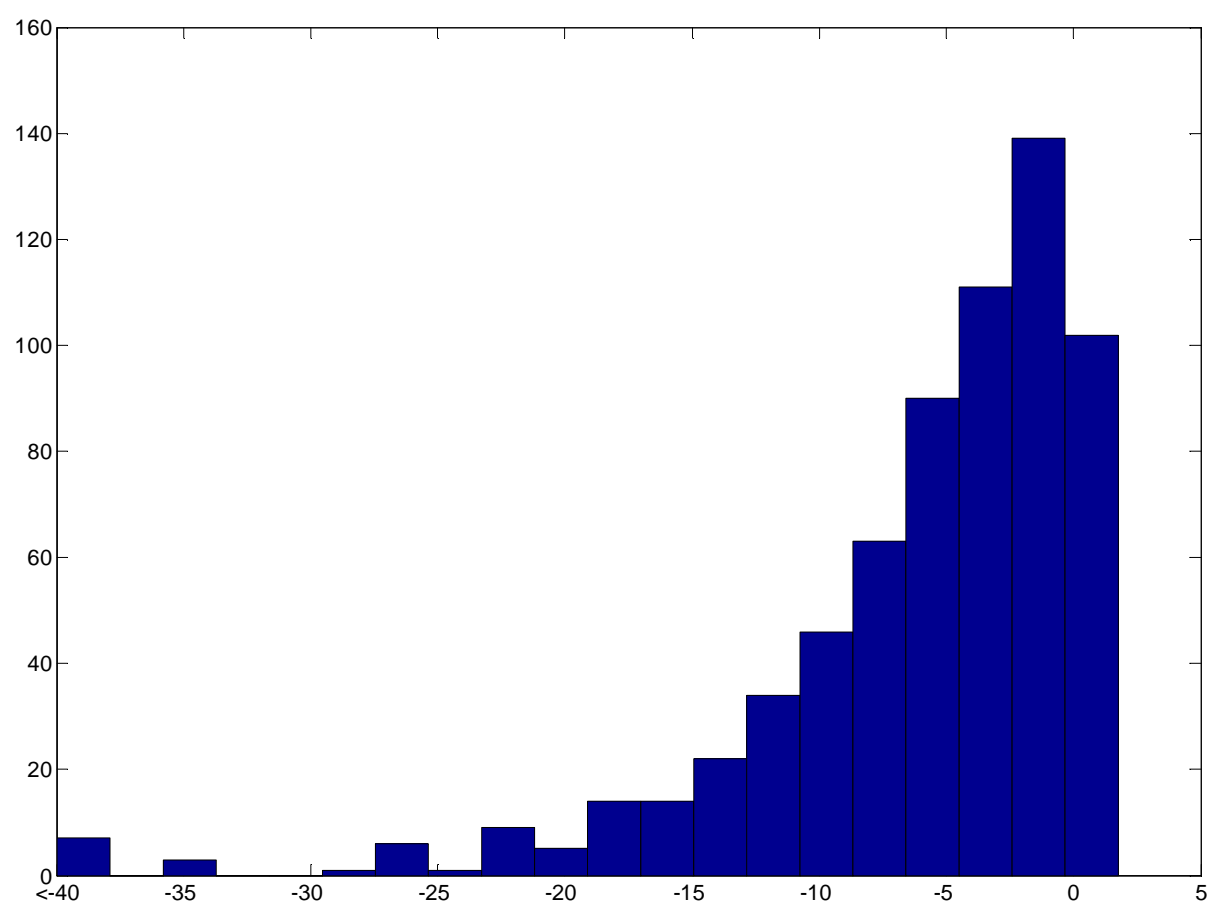

Note: GLS detrending conducted with constant. 
WORKING PAPERS*

Editor: Nils Gottfries

2009:11 Ranjula Bali Swain and Adel Varghese, The Impact of Skill Development and Human Capital Training on Self Help Groups. 28pp.

2009:12 Mikael Elinder. Correcting Mistakes: Cognitive Dissonance and Political Attitudes in Sweden and the United States. 25 pp.

2009:13 Sören Blomquist, Vidar Christiansen and Luca Micheletto: Public Provision of Private Goods and Nondistortionary Marginal Tax Rates: Some further Results. 41pp.

2009:14 Mattias Nordin, The effect of information on voting behavior. 34pp.

2009:15 Anders Klevmarken, Olle Grünewald and Henrik Allansson, A new consumer price index that incorporates housing. $27 \mathrm{pp}$.

2009:16 Heléne L. Nilsson, How Local are Local Governments? Heterogeneous Effects of Intergovernmental Grants. 41pp.

2009:17 Olof Åslund, Per-Anders Edin, Peter Fredriksson and Hans Grönqvist, Peers, neighborhoods and immigrant student achievement - evidence from a placement policy. $27 \mathrm{pp}$.

2009:18 Yunus Aksoy, Henrique S. Basso and Javier Coto-Martinez, Lending Relationships and Monetary Policy. 42 pp.

2009:19 Johan Söderberg, Non-uniform staggered prices and output persistence. $38 \mathrm{pp}$.

2010:1 Jonathan Gemus, College Achievement and Earnings. 43 pp.

2010:2 Susanne Ek and Bertil Holmlund, Family Job Search, Wage Bargaining, and Optimal Unemployment Insurance. 30 pp.

2010:3 Sören Blomquist and Laurent Simula, Marginal Deadweight Loss when the Income Tax is Nonlinear. $21 \mathrm{pp}$.

2010:4 Niklas Bengtsson, The marginal propensity to earn, consume and save out of unearned income in South Africa. 34 pp.

2010:5 Marcus Eliason and Henry Ohlsson, Timing of death and the repeal of the Swedish inheritance tax. 29 pp.

2010:6 Teodora Borota, Innovation and Imitation in a Model of North-South Trade. $44 \mathrm{pp}$.

\footnotetext{
${ }^{*}$ A list of papers in this series from earlier years will be sent on request by the department.
} 
2010:7 Cristiana Benedetti Fasil and Teodora Borota, World Trade Patterns and Prices: The Role of Productivity and Quality Heterogeneity. 24 pp.

2010:8 Johanna Rickne, Gender, Wages and Social Security in China’s Industrial Sector. 48 pp.

2010:9 Ulrika Vikman, Does Providing Childcare to Unemployed Affect Unemployment Duration? 43 pp.

2010:10 Sara Pinoli, Rational Expectations and the Puzzling No-Effect of the Minimum Wage. 56 pp.

2010:11 Anna Persson and Ulrika Vikman, Dynamic effects of mandatory activation of welfare participants. $37 \mathrm{pp}$.

2010:12 Per Engström, Bling Bling Taxation and the Fiscal Virtues of Hip Hop. $12 \mathrm{pp}$.

2010:13 Niclas Berggren and Mikael Elinder, Is tolerance good or bad for growth? $34 \mathrm{pp}$.

2010:14 Magnus Gustavsson and Pär Österholm, Labor-Force Participation Rates and the Informational Value of Unemployment Rates: Evidence from Disaggregated US Data. 10 pp.

2010:15 Chuan-Zhong Li and Karl-Gustaf Löfgren, Dynamic cost-bene $\mathrm{t}$ analysis of large projects: The role of capital cost. 8 pp.

2010:16 Karl-Göran Mäler and Chuan-Zhong Li, Measuring sustainability under regime shift uncertainty: A resilience pricing approach. 20 pp.

2010:17 Pia Fromlet, Rational Expectations And Inflation Targeting - An Analysis For Ten Countries. 38 pp.

2010:18 Adrian Adermon and Che-Yuan Liang, Piracy, Music, and Movies: A Natural Experiment. 23 pp.

2010:19 Miia Bask and Mikael Bask, Inequality Generating Processes and Measurement of the Matthew Effect. 23 pp.

2010:20 Jonathan Gemus, The Distributional Effects of Direct College Costs. 34 pp.

2010:21 Magnus Gustavsson and Pär Österholm, Does the Labor-Income Process Contain a Unit Root? Evidence from Individual-Specific Time Series. 26 pp.

See also working papers published by the Office of Labour Market Policy Evaluation http://www.ifau.se/ ISSN 1653-6975 